\title{
Kinetics of thermal grooving during low temperature recrystallization of pure aluminum
}

\section{Zhang, Yubin; Godfrey, Andy; Juul Jensen, Dorte}

\section{Published in:}

Materials Science Forum

Link to article, DOI:

10.4028/www.scientific.net/MSF.753.117

Publication date:

2013

Link back to DTU Orbit

\section{Citation (APA):}

Zhang, Y., Godfrey, A., \& Juul Jensen, D. (2013). Kinetics of thermal grooving during low temperature recrystallization of pure aluminum. Materials Science Forum, 753, 117-120.

https://doi.org/10.4028/www.scientific.net/MSF.753.117

\section{General rights}

Copyright and moral rights for the publications made accessible in the public portal are retained by the authors and/or other copyright owners and it is a condition of accessing publications that users recognise and abide by the legal requirements associated with these rights.

- Users may download and print one copy of any publication from the public portal for the purpose of private study or research.

- You may not further distribute the material or use it for any profit-making activity or commercial gain

- You may freely distribute the URL identifying the publication in the public portal

If you believe that this document breaches copyright please contact us providing details, and we will remove access to the work immediately and investigate your claim 


\title{
Kinetics of thermal grooving during low temperature recrystallization of pure aluminum
}

\author{
Yubin Zhang ${ }^{1, a}$, Andy Godfrey ${ }^{2, b}$ and Dorte Juul Jensen ${ }^{1, c}$ \\ ${ }^{1}$ Danish-Chinese Center for Nanometals, Section for Materials Science and Advanced \\ Characterization, Department of Wind Energy, Technical University of Denmark, DK-4000 Roskilde \\ Denmark \\ ${ }^{2}$ Laboratory of Advanced Materials, Dept. Material Science and Engineering, Tsinghua University, \\ Beijing 100084, P.R. China \\ ayubz@dtu.dk, bawgodfrey@tsinghua.edu.cn, ${ }^{\mathrm{c}}$ doje@dtu.dk
}

Keywords: boundary migration; thermal grooves; atomic force microscope (AFM); aluminum

\begin{abstract}
The migration of a recrystallization boundary in pure aluminum was followed during in situ annealing in a scanning electron microscope. The microstructure was characterized using the electron channeling contrast technique, and a typical stop-go grain boundary motion was observed during annealing. Thermal grooving associated with boundary migration on the inspected free surface was characterized after the in-situ experiment using atomic force microscopy. The results show that new thermal grooves develop at places where the recrystallization boundary segments remain stationary for a relatively long time. The kinetics of thermal grooving are determined and effects hereof on the boundary migration as well as influence on its formation from surface oxidation layer are discussed.
\end{abstract}

\section{Introduction}

The migration of grain boundaries plays a significant role in many materials processes. For example, during recrystallization new, dislocation-free nuclei develop and grow at the expense of a deformed matrix via the migration of the grain boundaries. Characterization techniques, such as electron channeling contrast (ECC) imaging and electron backscattering pattern (EBSP) analysis allow direct observation of boundary migration on a free surface of bulk material during in-situ or ex-situ annealing with both a high spatial resolution and a good time resolution. Such results have resulted in significant advances in the understanding of the boundary migration process. For example, in-situ [1] and ex-situ [2] investigations of boundary migration during recrystallization have directly revealed that the local deformed microstructure has a strong effect on the boundary migration, and stop-go motion of recrystallization boundaries has typically been seen.

However, it is recognized that 2D characterization techniques may suffer from surface problems. Among these problems, thermal grooving is particularly important for boundary migration, due to the fact that thermal grooves can form at the free surface associated with the boundary and thereby retard the migration of the boundary, which is not the case for boundary migration inside a bulk sample. When analyzing boundary migration based on 2D characterization, extra care is therefore needed in order to consider possible grooving-related problems. The kinetics of thermal grooving and its effects on boundary migration accompanying grain growth during high temperature annealing have been extensively studied by Mullins [3, 4] and Aristov [5]. In contrast, during recrystallization at low temperature, the driving force for boundary migration is orders of magnitude larger than that for grain growth, and the formation of thermal grooves and its effects on recrystallization boundary migration are less well understood.

The aim of the present study is to follow boundary migration during low temperature recrystallization and characterize the development of thermal grooving at a free surface during boundary migration. The results are used to investigate the kinetics of the thermal grooving and clarify its effects on boundary migration. 


\section{Experimental}

The material was $99.996 \%$ pure aluminum, annealed at $550^{\circ} \mathrm{C}$ for $24 \mathrm{~h}$ to obtain an initial grain size of several millimeters. This sample was cold rolled to $50 \%$ reduction in thickness at room temperature and subsequently rolled further to a total reduction of $86 \%$ in thickness at liquid-nitrogen temperature to avoid dynamic recrystallization during rolling. After rolling the sample was stored in a freezer at $-18^{\circ} \mathrm{C}$. Samples were cut and ground with $\mathrm{SiC}$ paper under water-cooling condition and followed by electropolishing using A2 solution at $2-5^{\circ} \mathrm{C}$ for $45 \mathrm{~s}$. In-situ annealing was carried out using a heating stage (DEBEN UK Ltd.) with a temperature range from $-25^{\circ} \mathrm{C}$ to $50^{\circ} \mathrm{C}$ in a Zeiss Supra 35 thermal field emission gun scanning electron microscope (SEM). The sample was heated to $50^{\circ} \mathrm{C}$ within 2 minutes and the migration of a recrystallizing boundary recorded (100s per frame interval in recording time of 86x100s) using the ECC technique. After annealing the surface morphology at the inspected surface area was characterized using atomic force microscopy (AFM).

\section{Results and discussion}

Example ECC images for the migration of a recrystallization boundary at three time steps are shown in Fig. 1a-c. From the full set of ECC images the boundary position can be extracted at every time step: tracings showing the recrystallization boundary at every $5^{\text {th }}$ time step are shown in Fig. $1 \mathrm{~d}$. The overall migration of the recrystallizing boundary is clearly non-uniform. In particular, the migration of the recrystallizing boundary is quite rapid in the early stage of annealing, slowing down with time, and then in the last stage of annealing remaining fixed for much of the boundary length. Locally the boundary migration is also very inhomogeneous: i) some boundary segments migrate faster than others; ii) a so-called stop-go motion [1, 2, 6] is observed locally. Three pinning positions, marked as A, B and C in Fig. 1d are seen, where recrystallizing boundary segments stop for a relatively long time. Pinning points where the recrystallizing boundary is held-up for a relatively short time are also seen (for example D in Fig. 1d).
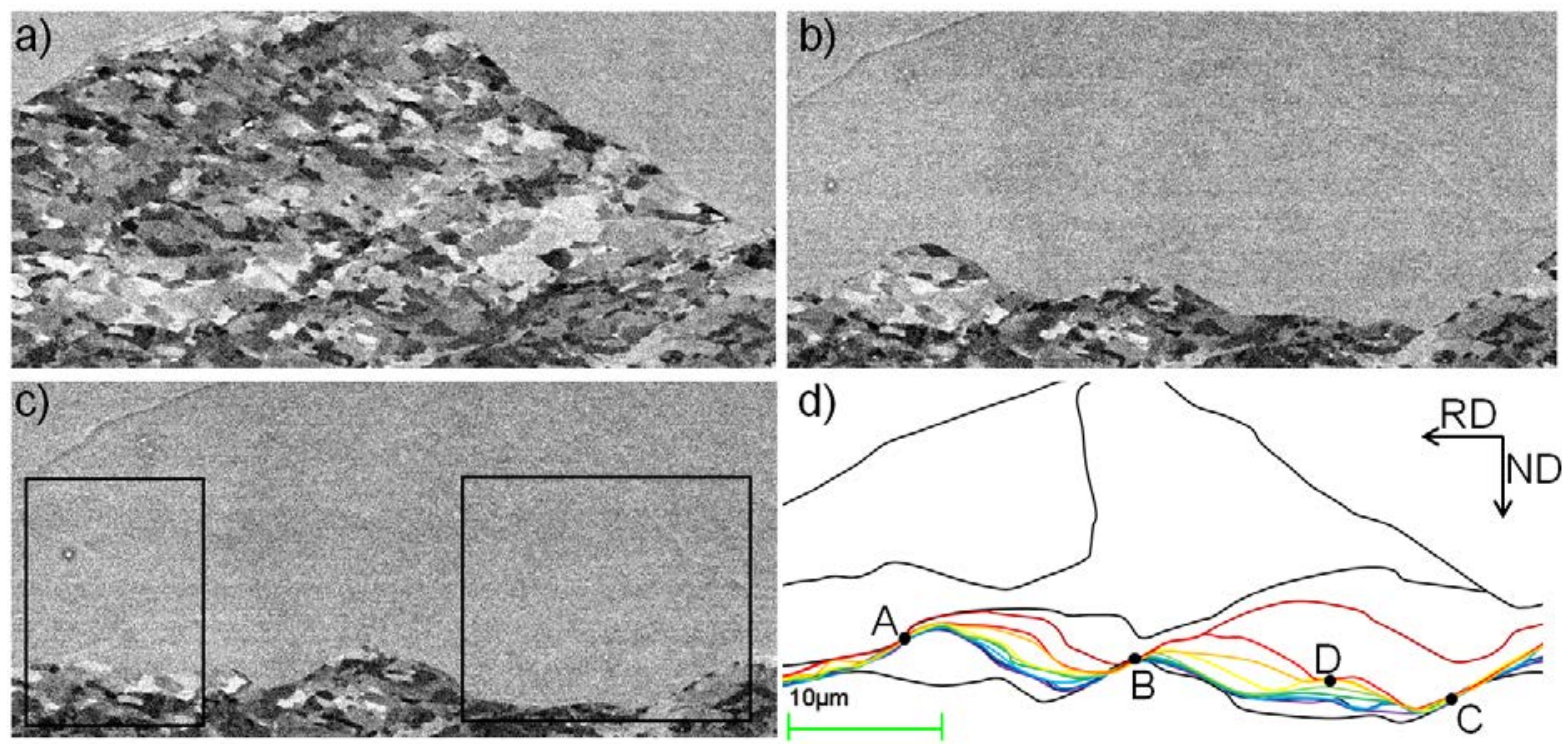

Fig. 1 ECC images showing the microstructure at different times: a) initial; b) $43^{\text {rd }}$ annealing time step (72min) and c) $86^{\text {th }}$ annealing time step (145min). d) Location of the recrystallization boundary at every $5^{\text {th }}$ time step during the entire annealing sequence. Rectangles in c) mark regions investigated by AFM scanning (see Fig. 2). Letters A-D in d) are used to mark the pinning locations.

A groove trace on the surface can be clearly seen in Figs. 1(b, c), coinciding with the trace of the recrystallization boundary at the starting position (Fig. 1a). This is referred to hereafter as the starting groove. High quality ECC images and AFM images of the regions marked in Fig. 1c, taken after the in-situ annealing, are shown in Fig. 2. These further reveal that some grooves have also developed 
during the boundary migration near the pinning point A, as marked by white arrows and numbers in Fig. 2a and b. Note that a part of the boundary has migrated beyond the position seen in the recorded ECC images (marked by black arrows in Fig. 2a, b): this migration is not considered further as it is not relevant to the current investigation. Comparing the grooves in Fig. 2a, b and the boundary traces in Fig. 1d, it can be seen that grooves develop at places where the segments of boundary remain fixed for at least 10 annealing time steps (corresponding to $\sim 17 \mathrm{~min}$ ). However, a groove is not seen at position D (Fig. 2c, d), even though part of the boundary was observed to remain at this position for 14 time steps (23min). This may relate to the fact that the non-moving segments at $\mathrm{D}$ are too small to be detected by AFM, or that the boundary type was somewhat different near D than elsewhere (e.g. a different boundary plane). In addition, no grooves are seen on the surface of the deformed matrix, implying that the new grooves do not originate from the deformed microstructure.

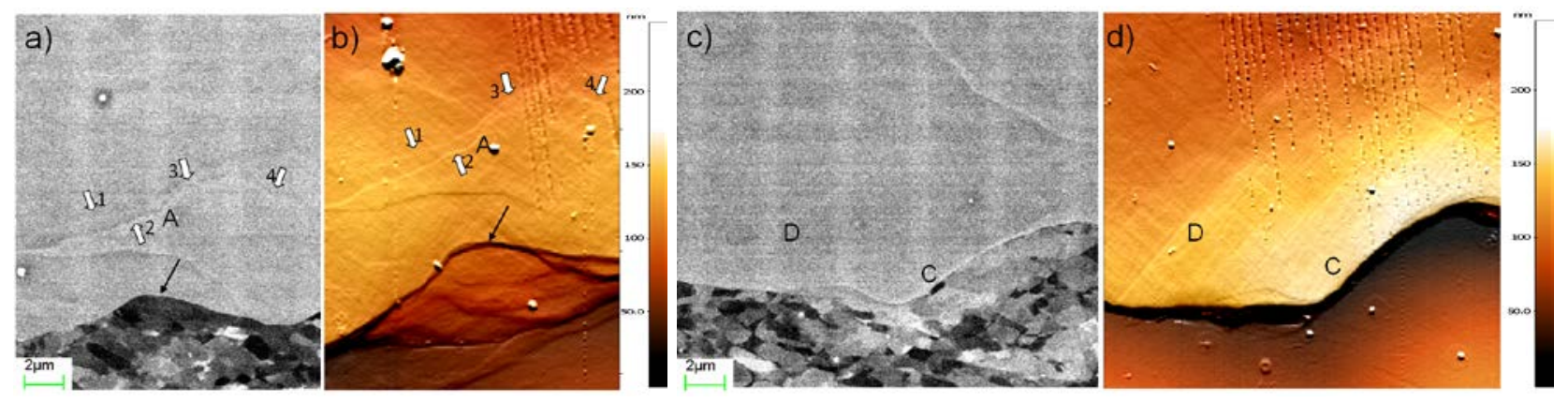

Fig. 2 a) and c) are high quality ECC images at the two rectangle regions in Fig. 1c; b) and d) are the surface mophology measured by AFM at same regions as in a) and b), respectively. Numbers in a) and b) are used to mark grooves. Letters A,C and D are the same as shown in Fig. 1d). The scratches on the AFM images are caused by the tip during the first unsuccessful measurement (but is of no consequence for the present results).

The developed grooves have been measured from AFM images (Fig. 2b) to be about 1-3.5nm deep, with a maximum depth of $\sim 3.5 \mathrm{~nm}$ at the pinning point A (i.e. one end of groove 2), where part of the boundary remained fixed for $\sim 58$ annealing time steps ( 97min). In Fig. $2 d$ part of the starting groove with a depth of about 3-4nm is seen. In both Fig. $2 \mathrm{~b}$ and $2 \mathrm{~d}$, large stair-type grooves can be seen at positions where the boundary remained fixed for a long duration (about 10 months) after the in-situ experiment, for example at position C. These grooves are 100-200nm in depth and are defined as final grooves.

According to Mullins' theory of thermal grooving [3], at a given temperature the depth, $d$, of the groove from the top to the root measured in the direction normal to the surface is given by:

$$
\log (d)=0.25 \log (t)+C
$$

where $\mathrm{C}$ is a constant depending on material property and temperature, and $t$ is the annealing time. Mullins' equation is developed for stationary grain boundaries. For our data the depth of the grooves at positions 1-4 is therefore plotted as a function of stopping time (at temperature of $50^{\circ} \mathrm{C}$ ) at these positions (i.e. when the boundary stayed stationary). As shown in Fig. 3 in a double logarithmic plot a clear linear relationship between grooving depth and stopping time can be seen. The slope of the fit is $k=0.28$, which is quite close to the theoretical value of 0.25 . Note that only the grooves developed during boundary migration (those illustrated in Fig. 2a, b) are considered here because the precise times and the temperatures for the

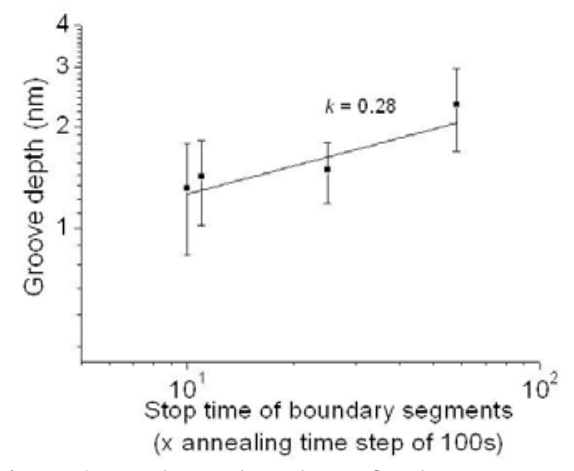

Fig. 3. The depth of the grooves plotted as a function of stopped time for boundary segments at positions 1-4 in Fig. 2b. 
development of starting and final grooves are unknown.

\section{Discussion}

The present results show that no grooves develop at the inspected free surface during boundary migration unless boundary segments remain in one position for a relatively long duration. At the temperature used in this study $\left(50^{\circ} \mathrm{C}\right)$ grooves associated with boundary segments stopped for $1-2 \mathrm{~h}$ only reach a depth of 2-3nm. Although these grooves are very small, they may still affect the boundary migration. For example, a boundary segment remained at position A for a relatively long time resulting in the development of groove No.2 ( $\sim 3 \mathrm{~nm}$ depth; see Fig. 1 and 2$)$. When this boundary segment restarted migration following detachment from this groove, it migrated a relatively large distance in a short time, which is a typical grooving effect. It should, however, be noted that when boundary segments detach from smaller grooves (e.g. with typical depths of 1-2nm, such as grooves No. 1, 3 and 4 in Fig. 2a), the boundary in such location can migrate in a quite continuous way, rather than in a large jump.

The oxidization layer formed on the free surface can retard thermal grooving on the free surface [7]. Aluminum is readily oxidized, and after electropolishing the fresh surface is oxidized very quickly (within 0.5h) even at room temperature to form an oxidization layer of $\gamma-\mathrm{Al}_{2} \mathrm{O}_{3}$ with a terminal thickness of $\sim 2 \mathrm{~nm}$ after $2 \mathrm{~h}[8,9]$. Thus for the present study, grooves with depth less than $\sim 2 \mathrm{~nm}$, (i.e. if boundary segments stop for less than $~ 30$ annealing time steps (Fig. 3)) do not exceed the surface oxide layer, and the effects of thermal grooving on the boundary migration may be ignored.

\section{Summary}

The migration of a recrystallization boundary in deformed pure aluminum has been followed using the ECC technique during in-situ annealing within a SEM. The results show that the migration of the recrystallization boundary is very non-uniform and that a stop-go motion is typically observed. Thermal grooves can develop if boundary segments stop migrating for relatively long times. When the grooves are large enough, they can affect the boundary migration and have to be considered when analyzing boundary migration.

\section{Acknowledgements}

The authors gratefully acknowledge support from the Danish National Research Foundation and the National Natural Science Foundation of China (Grant No. 51261130091) for the Danish-Chinese Center for Nanometals, within which this work was performed.

\section{References}

[1] Y.B. Zhang, A. Godfrey, D. Juul Jensen: Proceeding 31st Risø International Symposium. (2010) p. 497-503.

[2] Y.B. Zhang, A. Godfrey, D. Juul Jensen: Scripta Mater Vol64 (2011), p.331.

[3] W.W. Mullins: J. Appl. Phys. Vol 28 (1957), p. 333.

[4] W.W. Mullins: Acta Metall. Vol 6 (1958), p. 414.

[5] V. YU. Aristov, V. YE. Fradkov, S.L. Shvindlerman: Fizika Met. Metall. Vol 45 (1978), p. 997-1008.

[6] S. Schmidt, S.F. Nielsen, C. Gundlach, L. Margulies, X. Huang and D. Juul Jensen: Science Vol. 305 (2004), p. 229.

[7] N. Cabrera, N.F. Mott: Rep. Prog. Phys. Vol 12 (1949), p. 163.

[8] A.F. Beck, M.A. Heine, E.J. Caule, M.J. Pryor: Corrosion Sci. vol 7 (1967), p. 1-22.

[9] G. Gottstein, S.L. Shvindlerman: Scripta Metal. Vol 27 (1992), p. 1521. 